\title{
Muralf
}

INTERNACIONAL

\section{Segurança Hemisférica: reformulações desencontros no pós-Guerra Fria}

Hemispheric Security: reformulations

disagreements in the post-Cold War period LÍVIA PERES MILANI ${ }^{1}$

Resumo: O artigo faz um balanço da reformulação das instituições hemisféricas de Defesa e Segurança Internacional no período posterior à Guerra Fria. O objetivo é analisar o papel dos Estados Unidos da América (EUA) e contextualizar as modificações no quadro das relações interamericanas. Identifica-se que as reformas resultaram da conjuntura global, partiram de iniciativa dos EUA e geraram tanto resistência como aceitação na América do Sul. O texto foi dividido em duas partes, além da introdução e das considerações finais. Inicialmente, buscou-se reconstruir em linhas gerais o debate desenvolvido nos fóruns hemisféricos. Posteriormente, o texto aborda brevemente os desencontros entre os países do hemisfério, enfatizando as posições brasileiras. $\mathrm{O}$ artigo foi produzido com base em revisão de bibliografia, documentos oficiais dos organismos hemisféricos e, de maneira complementar, em pronunciamentos de líderes políticos da região.

Palavras-chave: Segurança Hemisférica; Brasil; EUA

Abstract: The article examines the hemispheric defense and international security institutions in the period after the end of the Cold War. The objective is to analyze the role of the United States and to contextualize the changes in the framework of inter-American relations. It identifies that the reforms resulted from the global context; were led from the United States and generated both resistance and acceptance in South America. The text has two main parts, in addition to the introduction and final considerations. Initially, we review the debate on hemispheric security that took place in the hemispheric forums during the 1990s. Subsequently, the text addresses the disagreements among the countries of the hemisphere, with emphasis on the Brazilian positions. The article was produced based on the literature review, hemispheric institutions official documents and, in a complementary manner, statements by political representatives.

Keywords: Hemispheric Security, Brazil, U.S.A.

\footnotetext{
${ }^{1}$ Doutoranda no Programa de Pós-graduação em Relações Internacionais San Tiago Dantas - UNESP, UNICAMP, PUC-SP. Pesquisadora Visitante do Centro de Estudos Latinos Americanos (CLAS) da Georgetown University. Endereço para correspondência: Programa de Pós-Graduação em Relações Internacionais San Tiago Dantas UNESP - UNICAMP - PUC-SP, Praça da Sé, 108 - $3^{\circ}$ Andar - Sé - São Paulo - SP - CEP: 01001-900, Brasil. E-mail: livialpm@ gmail.com ORCID: https://orcid.org/0000-0003-4300-205X
} 


\section{Introdução}

A década de 1990 foi um momento de intensa atividade nas organizações internacionais dedicadas à segurança internacional. O fim da bipolaridade gerou um momento de reformulação e expansão da ordem liberal internacional, sendo que o arcabouço institucional construído após a Segunda Guerra Mundial foi preservado, porém reformulado (Pecequilo, 2011). Assim, novos temas passaram a ser abordados pelo Conselho de Segurança da Organização das Nações Unidas (CSONU) e os debates sobre o futuro da Organização do Tratado do Atlântico Norte (OTAN) ganharam relevo, resultando na revisão de sua missão e na incorporação de novos membros.

O contexto global impactou também nas instituições do subsistema americano, o que desencadeou debates sobre suas reformas. Os mecanismos americanos de cooperação haviam sido desgastados pelos desencontros entre os Estados Unidos da América (EUA) e a América Latina nos anos 1980, contexto que tendia a ser superado nos anos 1990. A redemocratização e a liberalização econômica na América Latina geraram expectativas de mudança nas relações interamericanas e de início de um período cooperativo. Os governos latino-americanos aderiam ao neoliberalismo, ideologia dominante no período, à ordem liberal internacional e buscavam reconstruir suas relações com a potência global. Os EUA, por sua vez, propuseram uma iniciativa de integração regional pautada no livre-comércio.

Embora as relações interamericanas tenham sido amplamente discutidas do ponto de vista econômico, especialmente no que se refere às negociações da Área de Livre Comércio das Américas (ALCA), menor atenção foi atribuída às questões de segurança internacional. Tendo em vista esse cenário, o artigo faz um balanço sobre como as instituições pan-americanas sobre Defesa e Segurança Internacional foram reformuladas no período posterior à Guerra Fria. Dentro dos limites desse texto, o objetivo é analisar a liderança dos EUA nesse processo e contextualizar as modificações no quadro das relações interamericanas.

Objetiva-se também apontar para a existência de reações de resistência sulamericanas, o que será feito através de uma breve análise das posições brasileiras. $\mathrm{O}$ caso brasileiro é importante por seu peso regional - em termos econômicos, populacionais e geográficos - e porque o país liderou a construção do Conselho de Defesa Sul- 


\section{Muralf}

INTERNACIONAL

americano (CDS), o que torna suas posições sumamente relevantes no processo de questionamento da hegemonia dos EUA ${ }^{2}$.

O texto foi dividido em duas partes, além da introdução e das considerações finais. Inicialmente, buscou-se reconstruir em linhas gerais o debate sobre a segurança hemisférica no pósGuerra Fria, que ocorreu em duas instâncias principiais: a Comissão de Segurança Hemisférica (CSH) da Organização dos Estados Americanos (OEA) e a Conferência de Ministros de Defesa das Américas (CMDAs). Em seguida, o texto aborda brevemente os desencontros entre os países do hemisfério, com foco na posição brasileira. $\mathrm{O}$ artigo foi produzido com base na revisão de bibliografia e em documentos oficiais da OEA e da CMDAs e, de maneira complementar, em pronunciamentos de líderes políticos.

\section{A Segurança Hemisférica no Pós- Guerra Fria}

\footnotetext{
${ }^{2}$ Não foram incluídos outros países na análise por limitações estruturais e de espaço. Contudo, ressalta-se a importância de analisar outras posições; tanto as mais críticas aos EUA, como a da Venezuela, como as mais alinhadas, especialmente a da Colômbia, para se ter uma visão mais completa do processo de questionamento à hegemonia dos EUA. Também se destaca a posição argentina, país que possuiu liderança no âmbito do CDS, tanto em sua consolidação quanto na formulação de conceitos.
}

Mural Internacional

V. 9 |N. 1

JAN-JUN 2018
Durante a década de 1990, as mudanças na conjuntura hemisférica foram relevantes, especialmente do ponto de vista da segurança internacional. A alteração na configuração de poder internacional ampliava a capacidade de liderança estadunidense nas Américas, já que não haviam outras potências mundiais disputando sua hegemonia (Smith, 2008). Por outro lado, a redemocratização e a liberalização comercial, aproximavam os dois lados do hemisfério e havia expectativa de cooperação por parte dos países do Sul (Pecequilo, 2011).

Com a mudança do ambiente estratégico global, as preocupações estratégicas regionais dos EUA recaíram sobre a redemocratização, a liberalização econômica e as ameaças não tradicionais, especialmente $\mathrm{O}$ narcotráfico. A defesa da democracia era vista como um aspecto da segurança hemisférica e havia preocupação com a condução civil da defesa e com as relações entre civis e militares (Perry, Primorac, 1994). Na perspectiva dos EUA, as principais ameaças do período da Guerra Fria - o comunismo e a insurgência ${ }^{3}$ - haviam sido substituídas por questões complexas como o crime

\footnotetext{
${ }^{3}$ Em 1954, o possível surgimento de um governo comunista foi identificado como ameaça hemisférica por meio de resolução da OEA (Herz, 2008). A preocupação dos EUA com o tema tornou-se mais premente após a Revolução Cubana (Martins Filho, 2005)
} 
organizado, o tráfico de drogas, pessoas e armas, que demandavam ações multilaterais e coordenadas (U.S. Department of State, 2016).

O narcotráfico já era percebido como uma ameaça à segurança nacional estadunidense desde o governo de Richard Nixon (1969-1974). Naquela administração, teve início a "guerra às drogas" e foi criada uma agência de segurança específica a Drug Eforcement Administration (DEA), com jurisdição para atuar internacionalmente (Rodrigues, 2012). Nos anos 1990, essa preocupação foi elevada à prioridade, juntamente com outras questões, como lavagem de dinheiro e corrupção, sintetizadas pela noção de crime organizado transnacional (Pereira, 2015). A partir de 2001 houve um esforço para relacionar o combate ao crime organizado com as ações antiterrorismo, sendo que se destacava a fragilidade estatal provocada pelo crime como uma possível porta de entrada para os terroristas (Villa, 2014).

A mudança na percepção de ameaças desencadeada pelo fim da Guerra Fria teve consequências operacionais e, assim, as missões das Forças Armadas latino-americanas entraram em debate. $\mathrm{Na}$ perspectiva dos EUA, as forças policiais não eram capazes de lidar com o narcotráfico, assim os militares latino- americanos e estadunidenses foram empregados de forma crescente para lidar com o problema. No período, o Comando $\mathrm{Sul}^{4}$ passou por uma reformulação para atuar em missões antinarcóticos e de assistência humanitária (United States Southern Command, s/d).

No contexto de modificações de conjuntura e de demanda por atualização doutrinária, a tática adotada pelos EUA para renovar sua liderança no Hemisfério Ocidental baseou-se na valorização das instituições multilaterais e na ênfase à cooperação. O movimento institucionalista dos EUA visava "recompor doutrinariamente $\mathrm{O}$ continente americano como sua área de segurança nacional", discutir e unificar uma agenda hemisférica de segurança e identificar as ameaças comuns ao continente (Saint-Pierre 2011, p. 410). Buscava-se revitalizar a OEA, torná-la capaz de lidar com os desafios de segurança hemisférica e promover a cooperação.

Contudo, na impossibilidade disso, o caminho seria a adoção de tratados bilaterais e $\mathrm{o}$ aumento do unilateralismo por parte da potência (Perry; Primorac, 1994).

\footnotetext{
${ }^{4}$ O Comando Sul é um dos dez Comandos de Combate do Departamento de Defesa dos EUA. Sua área de responsabilidade refere-se a toda a região do continente americano a sul do México.
} 


\section{Muralf}

INTERNACIONAL

Sob liderança dos EUA, a OEA iniciou o debate sobre as questões de segurança hemisférica em 1991, quando a Assembleia Geral decidiu pela criação de um Grupo de Trabalho para discutir o tema. No ano seguinte, 1992, foi criado o Comitê Especial sobre Segurança Hemisférica e, em 1995, o Comitê tornou-se um organismo permanente da OEA, a Comissão de Segurança Hemisférica (CSH).

Nas reuniões promovidas pela $\mathrm{CSH}$, os representantes dos países americanos buscaram repensar o conceito de segurança. Nas Conferências Regionais Sobre Medidas de Fortalecimento da Confiança, realizadas em 1995 e em 1998, o conceito de segurança cooperativa ganhou relevo. Foram abordados temas referentes à cooperação militar, às medidas de fomento a confiança mútua, à transparência em gastos de Defesa, ao compartilhamento de informações sobre políticas de defesa e limitação dos gastos militares (Organização Dos Estados Americanos, 1995).

Paralelamente aos esforços na OEA, os EUA convocaram as Conferências de Ministros de Defesa das Américas (CMDAs) a partir de 1995. Nestas, o conceito de segurança cooperativa também esteve presente. Apesar da primeira reunião não produzir
Mural Internacional

V. 9 | N. 1

JAN-JUN 2018 declaração oficial, o informe produzido pelos EUA listava os "Princípios de Williamsburg": 1) promoção dos valores democráticos, reconhecimento do papel das Forças Armadas na defesa da soberania nacional, 3) subordinação dos militares aos governos democráticos, 4) ampliação da transparência através da troca de informações sobre gastos de defesa, 5) negociação como forma de resolução das controvérsias e 6) cooperação em missões de paz e no combate ao narcotráfico (United States Department of Defense, 1995).

A preocupação com a definição da segurança hemisférica continuou presente no pós-2001. A Comissão de Segurança Hemisférica realizou um estudo sobre os conceitos de segurança nas Américas e preparou a Conferência Especial sobre Segurança que ocorreu em 2003. Nesta, os ministros de Relações Exteriores reconheceram que a nova arquitetura de segurança continental deveria ser flexível, respeitando as particularidades subregionais e nacionais. Ademais, apresentavam um novo conceito: a segurança multidimensional. $\mathrm{Na}$ declaração final, definiam que Nossa nova concepção da segurança no
Hemisfério é de alcance
multidimensional, inclui as ameaças
tradicionais e as novas ameaças, 
preocupações e outros desafios à segurança dos Estados do Hemisfério, incorpora as prioridades de cada Estado, contribui para a consolidação da paz, para o desenvolvimento integral e para a justiça social e baseia-se em valores democráticos, no respeito, promoção e defesa dos direitos humanos, na solidariedade, na cooperação e no respeito à soberania nacional (Organização dos Estados Americanos, 2003).

Parte da literatura destaca que o conceito de "segurança multidimensional" adotado é problemático por ser excessivamente amplo, abrangendo diferentes questões pelas lentes da segurança e sugerindo a militarização no trato de questões essencialmente políticas, sociais ou econômicas (Mathias, Fazio, 2004; Saint-Pierre, 2011; Chillier; Freeman, 2005). A tendência de alargamento pode ser notada pela identificação de ameaças que foi realizada na Conferência. A declaração final apontava ameaças de diversos âmbitos, apresentadas como comuns ao hemisfério ocidental. Eram elas: 1) o terrorismo, o crime e as conexões entre eles; 2) a pobreza extrema e a exclusão social 3) os desastres naturais, doenças e a deterioração do meio ambiente; 4) o tráfico de pessoas; 5) os ataques cibernéticos; 6) a possibilidade de acidentes com material radioativo e resíduos tóxicos e 7) a possibilidade de acesso de armas de destruição em massa por terroristas (Organização dos Estados Americanos, 2003).

As demandas dos EUA foram especialmente atendidas no conceito de multidimensionalidade e na listagem de ameaças. Em sua exposição, o representante dos EUA havia apontado como ameaças: o terrorismo, o tráfico de drogas, o crime transnacional, as doenças e os desastres naturais. $\mathrm{O}$ representante ressaltou também o apoio a Colômbia no combate ao "narcoterrorismo" e declarou que "as ameaças contemporâneas são multidimensionais. A defesa bem-sucedida é multidimensional" (Organization of American States, 2003, tradução nossa). Entretanto, a influência exercida pelos EUA não foi total. As temáticas da pobreza, da exclusão, da justiça social e do desenvolvimento, também citadas na declaração, são mais próximas da linguagem e demandas dos países latino-americanos. A noção de "narcoterrorismo" tampouco foi incorporada.

Cabe ressaltar que após a Conferência Especial sobre Segurança foi criada uma Secretaria de Segurança Multidimensional, como órgão do Conselho Permanente da OEA, com o objetivo de auxiliar nos trabalhos e discussões da Comissão de Segurança Hemisférica. A Secretaria conta com 


\section{Muralf}

INTERNACIONAL
Mural Internacional

V. 9 |N. 1

JAN-JUN 2018 quatro departamentos: a Comissão Interamericana para o Controle do Abuso de Drogas; o Comitê Interamericano contra o Terrorismo; o Departamento de Segurança Pública e o Departamento contra a Delinquência Organizada Transnacional.

A noção de multidimensionalidade já havia estado presente na Conferência de Ministros de Defesa realizada em 2002, no Chile. Naquele momento, os representantes ressaltaram a multidimensionalidade das ameaças, a necessidade de esforços colaborativos no combate ao narcotráfico e ao crime organizado e reconheceram a liberdade de cada Estado em empregar os meios que considerar necessários para lidar com tais problemas (V Conferência de Ministros de Defensa das Américas, 2002). Já em 2006, na Conferência de Ministros de Defesa realizada em Manágua, a declaração final afirmava a necessidade de fortalecer e modernizar as forças de segurança e defesa, em vista das ameaças, preocupações e desafios identificados em 2003 (VII Conferência de Ministros de Defesa das Américas, 2006). Assim, o alargamento da segurança pela noção de multidimensionalidade, abarcando temas não militares, foi trasladado para o campo da Defesa, sugerindo uso dos militares em segurança pública (SaintPierre, 2011).
Em 2006, como resultado de uma discussão que provinha da década anterior, os países do continente americano aprovaram um novo estatuto para a Junta Interamericana de Defesa $\left(\mathrm{JID}^{5}\right)$, que a estabeleceu como uma entidade da OEA. Os países americanos definiram a JID como um órgão de assessoramento e educação em temas militares e não incorporavam $o$ alargamento das ameaças em seu estatuto. Contudo, tendo em vista a concepção de segurança multidimensional adotada pelo organismo político pan-americano, a incorporação da JID à sua institucionalidade intensifica a tendência de militarização no combate às ameaças transnacionais.

A partir de 2008, a CSH deu o início à realização das Reuniões de Ministros em Matéria de Segurança Pública das Américas. A semelhança dos temas discutidos pelos ministros de Defesa e de Segurança Pública tende a gerar uma aproximação e sobreposição entre os dois ministérios. As discussões no âmbito hemisférico, da qual participam tanto os ministérios dedicados à segurança pública quanto os dedicados à defesa, têm como preocupação central

\footnotetext{
${ }^{5}$ A JID é um organismo estabelecido em 1942 que congrega técnicos militares dos Estados-membros e busca promover a cooperação e estudos hemisféricos no tema da Defesa. Mais informações: http://www.jid.org/?page_id=285
} 
as ameaças não tradicionais, especialmente o narcotráfico e o terrorismo.

\section{Os desencontros entre os EUA e a América do Sul}

A reformulação dos conceitos de segurança hemisférica encontrou aceitação e críticas, em um processo no qual a América do Sul buscou diferenciar-se do hemisfério, construindo uma institucionalidade própria. Durante os anos 1990, as resistências partiram especialmente do Brasil. O diplomata Andrade Pinto (2015) relata que o Brasil acolheu com desconfiança inicial tanto a discussão de segurança cooperativa quanto as CMDAs, em razão principalmente da preocupação com a assimetria de poder. $\mathrm{O}$ autor aponta que a mudança conceitual sobre segurança e o emprego das Forças Armadas em questões internas era visto com menor desconfiança pela Presidência, mas havia resistência por parte dos militares.

Nas reuniões da OEA, os representantes brasileiros expressavam resistência com relação ao foco em ameaças não tradicionais e a adoção de medidas de confiança mútua em um contexto de intensa assimetria (Pinto, 2015). A percepção brasileira era de que os EUA buscavam promover a limitação dos gastos militares convencionais na
América Latina. No caso das reuniões de Ministros de Defesa, pesava também a institucionalidade brasileira, com três ministérios militares e resistências à condução civil. Contudo, a posição brasileira tornou-se menos crítica após a criação do Ministério da Defesa ${ }^{6}$ (1999) e o Brasil passou a atuar mais fortemente nas discussões, buscando também projetar sua própria agenda (Pinto, 2015).

Na primeira década do século XXI, os desencontros entre a América do Sul e os EUA tornaram-se mais claros. A mudança tem relação tanto com ações dos EUA quanto com posturas dos países ao sul do continente. O governo George W. Bush significou uma modificação importante nas táticas e forma de atuação dos EUA e uma priorização do unilateralismo sobre o multilateralismo. Na América Latina, os acordos bilaterais, especialmente com os países exportadores de narcóticos, ganharam importância em detrimento dos esforços multilaterais. O início do Plano Colômbia, em 2000, institucionalizou a assistência antinarcóticos ao país e, a partir de 2001, a ajuda militar foi expandida, passando a abranger também a guerra

${ }^{6}$ Até então, o Brasil contava com três ministérios militares separados: o da Aeronáutica, o do Exército e o da Marinha. 


\section{Muralf}

INTERNACIONAL

interna contra a insurgência (Vaicious; Isacson, 2003).

Por outro lado, a ascensão de governos sul-americanos que buscavam maior afirmação nacional frente aos EUA ampliou a distância entre o restante da região e a potência (Battaglino, 2012). Os governos de Venezuela, Equador e Bolívia assumiram posição antiimperialista, com retórica explicitamente crítica à potência. Os governos da Argentina e, principalmente, do Brasil, atuaram de forma mais sutil, buscando diversificar parcerias, fomentar a integração regional e diminuir a dependência. Contudo, os matizes não impediram uma crescente diferenciação entre esta região e o restante do hemisfério.

Os países da América do Sul buscaram criar alternativas à cooperação hemisférica, especialmente através de instituições sub-regionais. A criação de uma institucionalidade sul-americana foi liderada pelo Brasil num processo de construção de um espaço geopolítico diferenciado da totalidade das Américas. Desde os anos 1980, o país busca fomentar processos de cooperação sub-regional. Durante os anos 1990, esse processo teve como foco o Mercosul e, nos anos 2000, a criação da União das Nações Sul-americanas (Unasul). Parte da literatura interpretou
Mural Internacional

V. 9 | N. 1

JAN-JUN 2018 que essa postura tinha conotações geopolíticas e era um contraponto à perspectiva estadunidense de tratar o Hemisfério Ocidental de forma homogênea (Bandeira, 2010).

A intervenção do Ministro das Relações Exteriores, Celso Amorim, na Conferência Especial sobre Segurança de 2003 foi no sentido de ressaltar as diferenças regionais nas Américas, sugerindo a inexistência de um todo:

Ao constatarmos a existência de ameaças e desafios comuns [...] devemos também reconhecer a importância das especificidades tanto nacionais, como regionais e sub-regionais. [...] O projeto, para nós estratégico, da integração regional permitiu-nos superar percepções de rivalidade [...] Dispomos de uma identidade estratégica própria (Amorim, 2003, grifo nosso).

Seguindo essa orientação de diferenciação sub-regional, em 2008 foi criado o Conselho de Defesa Sulamericano $\left(\mathrm{CDS}^{7}\right)$ no âmbito da UNASUL. No mesmo ano de criação do CDS (2008), o governo brasileiro divulgou a Estratégia Nacional de Defesa (END) que propunha a retomada de projetos estratégicos por parte do país e representava a possibilidade de revitalização da indústria de defesa

\footnotetext{
${ }^{7}$ A bibliografia sobre o CDS - analisado sob diversos ângulos e perspectivas - é extensa. Ver, por exemplo: Battaglino (2012); Flemes; Nolte; Wehner, (2011) Fuccille; Rezende (2013).
} 
nacional (DAGNINO, 2010). O documento complementava a abordagem do Ministério das Relações Exteriores, o qual propunha uma Política Exterior assertiva. Assim, a proposta do CDS alinhava-se à Política Exterior brasileira, naquele momento guiada pela busca de ampliar a autonomia nacional.

O CDS não incorporou o conceito de segurança multidimensional e buscou separar claramente as agendas de defesa e segurança, diferenciando-se dos organismos pan-americanos em sua agenda (Saint-Pierre, 2011). Ao focar cada vez mais no tema da defesa dos recursos naturais e buscar uma identidade estratégica comum, começava a ser delineado um modelo de cooperação dissuasória, entendida como cooperação interna para dissuadir externamente (Vittelli, 2016).

A criação do CDS gerou uma percepção de debilidade do sistema hemisférico e de diminuição da hegemonia dos EUA. Celi de la Torre (2012, p. 282, tradução nossa), por exemplo, analisa esse cenário como de "declínio do poder relativo dos EUA sobre a América Latina" e de surgimento da América do Sul como região autônoma. Contudo, os ensaios de resistência à hegemonia dos EUA tiveram limitações importantes. $\mathrm{O}$ CDS apresentou obstáculos significativos decorrentes da falta de coesão na percepção de ameaças e da pluralidade de agendas. Desde o início, a "cooperação dissuasória" também possuía restrições importantes: a criação do CDS apenas ocorreu após uma visita de do então Ministro da Defesa brasileiro, Nelson Jobim, aos EUA.

Ademais, a separação entre defesa e segurança no CDS não correspondeu a uma mudança na configuração interna dos Estados e a atuação das Forças Armadas sul-americanas em missões de combate ao crime acentuou-se. Durante a gestão de Jobim, as Forças Armadas brasileiras passaram a atuar de forma mais recorrente em missões internas, de Garantia da Lei e da Ordem, ao contrário do que a criação do CDS parecia indicar (Lima, 2015). Essa questão é relevante pois a intensificação do emprego interno dos militares impacta em sua capacidade de atuação dissuasória frente a ameaças externas (Saint-Pierre, 2011).

Além das limitações da resistência sulamericana, houve uma reação dos EUA, que buscaram manter e fortalecer seus contatos com os militares da região, com destaque para a atuação do Comando $\mathrm{Sul}^{8}$. Em 2007, o Comandante

\footnotetext{
${ }^{8}$ O Comando Sul é uma das dez unidades de comando unificado do Departamento de Defesa dos EUA, sua área de
} 


\section{Muralf}

INTERNACIONAL
Mural Internacional

V. 9 | N. 1

JAN-JUN 2018 da unidade militar, Almirante James Stavridis, enfatizou a necessidade de manter a cooperação militar mesmo em um clima político adverso. Em suas palavras, "temos a complicada tarefa de manter relações funcionais com as forças de segurança [...] em um contexto de liderança política antagônica" (United States Southern Command, 2007, tradução nossa).

A criação do CDS não significou uma contraposição coesa ao paradigma de segurança originado nos EUA $e$ dominante nas instituições hemisféricas. Havia diversidade nos relacionamentos bilaterais dos países da América do Sul com os EUA e na adesão às instituições hemisféricas. Ademais, a fragilidade das instituições hemisféricas não corresponde, necessariamente, à fragilidade da hegemonia dos EUA na América Latina. As divergências entre os países do continente na OEA foram recorrentes durante o século $\mathrm{XX}$ e não chegaram a prejudicar a liderança estadunidense no continente, que se reafirmou nos anos 1990.

De forma semelhante, o questionamento à hegemonia dos EUA no início do século XXI, enfraqueceu-se especialmente a partir de 2016. As mudanças políticas no Brasil, Argentina

responsabilidade abrange o território das Américas e Caribe ao sul do México. e Equador levaram a mudanças nas Políticas Exteriores desses países e busca de realinhamento aos EUA. Desde então, a Unasul passa por uma crise, originada pela falta de consenso regional, o que significou obstrução do processo decisório. Em abril de 2018, seis países - Argentina, Brasil, Chile, Colômbia ${ }^{9}$ Paraguai, Peru suspenderam sua participação no organismo. Embora tal decisão não seja definitiva, a curto prazo, impede a atuação do bloco, tanto por limitar seu orçamento, como pela decorrente ausência de encontros com a totalidade dos governos da região.

\section{Considerações Finais}

Considerando a reformulação das instituições de segurança panamericanas e as resistências sulamericanas, conclui-se que, como ressaltado pela literatura, houve liderança dos EUA na reformulação da noção de segurança hemisférica (SaintPierre, 2011; Mathias, Fazio, 2004; Celi de la Torre, 2012). O país incentivava a mudança nas missões das Forças Armadas latino-americanas, com enfoque no combate ao crime organizado transnacional. A partir dos anos 2000, os países sul-americanos buscaram aumentar graus de autonomia,

\footnotetext{
${ }^{9}$ Em agosto de 2018, a Colômbia anunciou sua saída definitiva do bloco regional.
} 
o que ocorreu a partir da criação do CDS. Essa postura levou a percepção de diminuição da hegemonia dos EUA na região. Contudo, não impediu a incorporação do paradigma de segurança hemisférico, com crescente ampliação do uso das Forças Armadas em questões de segurança pública por todos os países do hemisfério - com a exceção do Chile e com escopos diferentes em cada país.

A reação da América do Sul à política de segurança dos EUA foi heterogênea, mesmo nos países focais do combate ao narcotráfico. A Colômbia buscou ajuda dos EUA e instrumentalizou seu discurso para atrair atenção do país do Norte. Outros países, como a Bolívia e a Venezuela, responderam às políticas dos EUA com retórica anti-imperialista, sem necessariamente separar Defesa e segurança pública, ou limitar a atuação interna dos militares. Brasil e Argentina optaram por buscar certa autonomia sem contrapor-se aos EUA, porém ampliaram gradualmente o uso interno das FFAA. A diversidade de reações é um indício de que havia também importantes constrangimentos e pressões internas em prol de uma concepção de segurança ampliada. Assim, não é possível afirmar que os países incorporaram o paradigma de segurança hemisférico simplesmente por pressões externas.

Atribuir o alargamento da Defesa simplesmente à posição dos EUA é uma visão simplista, que não condiz com a complexidade dos processos. É imperativo analisar como se desenrolaram as relações especificamente bilaterais com os EUA e se havia proximidade entre interesses do país do norte e grupos internos, especialmente militares, na América do Sul. O cenário político sul-americano mais recente sugere que, mesmo quando os governos latino-americanos tinham uma posição de afirmação nacional e busca de autonomia frente aos EUA, haviam grupos internos que demandavam maior aproximação com a potência e ressaltavam as ameaças nãotradicionais.

\section{Bibliography}

Amorim, C. (2003). 'Discurso do Senhor Ministro de Estado das Relações Exteriores da República Federativa do Brasil'. Organização dos Estados Americanos. Conferência Especial sobre Segurança. Disponível em: https://www.oas.org/csh/CES/discursos.asp [Acesso em: 08 Out. 2018]. 


\section{Muralf}

INTERNACIONAL

Mural Internacional

V. $9 \mid$ N. 1

JAN-JUN 2018

\section{1}

Bandeira, L. A. M. (2010). Geopolítica e Política Exterior. Estados Unidos, Brasil e América do Sul. Brasília: FUNAG.

Battaglino, J. (2012). 'Defence in a post-hegemonic regional agenda: the case of the South American defence council', in: Riggirozzi, P. Tussie, D. The Rise of PostHegemonic Regionalism. Springer.

Celi de la Torre, P. (2012) 'El Anclaje Suramericano de Integración y Seguridad Regional'. Cuadernos de Estrategia. Los Desafíos de la Seguridad en Iberoamérica. Madrid: Ministerio de Defensa: Instituto Español de Estudios Estratégicos: Instituto Universitario General Gutiérrez Mellado.

Chillier, G.; Freeman, L. (2005). El Nuevo Concepto de Seguridad Hemisférica de la OEA: Una Amenaza en Potencia. Washington Office on Latin America.

Dagnino, R (2010). A Indústria de Defesa no Governo Lula. São Paulo, Editora Expressão Popular.

Flemes, D.; Nolte D.; Wehner, L. (2011). 'Una comunidad de seguridad regional en formación: la Unasur y su Consejo de Defensa'. Estudios Internacionales, pp. 105127.

Fuccille', A. Rezende, L. C (2013). 'Complexo regional de segurança da América do Sul: uma nova perspectiva', Contexto Internacional, 35(1), p. 77-104.

Herz, M. (2008). 'Does the OAS Matter?', London School of Economics: Crisis States, Working Paper Series, n.2.

Lima, R. C. (2015). A articulação entre a política externa e a política de defesa no Brasil: uma Grande estratégia inconclusa. Dissertação (Mestrado em Relações Internacionais). Universidade Estadual Paulista, São Paulo, 2015.

Martins Filho, J. R. (2005). 'As Políticas Militares dos EUA para a América Latina (1947-1989)'. Teoria e Pesquisa, v.46.

Mathias, S. K. Fazio, E. 'Nuevas amenazas y su impacto sobre las fuerzas armadas brasileñas', Revista Fuerzas Armadas y Sociedad, 18 (3-4), pp. 53-81. 
Organização dos Estados Americanos (1995). Declaração de Santiago sobre Medidas de Fortalecimento da Confiança e da Segurança. [online]. Disponível em: http://www.oas.org/CSH/portuguese/declarsantiago.asp. [Acesso em: 01 Out. 2018]

Organização dos Estados Americanos. Projeto de Declaração Sobre Segurança nas Américas (2003). Conferência Especial sobre Segurança. Disponível em: https://www.oas.org/csh/CES/pr/. [Acesso em: 01 Out. 2018].

Organization of American States (2003). Special Conference on Security. Remarks by his Excellency Marc Grossman under Secretary for Political Affairs of the State Department of the United States. Disponível em: https://www.oas.org/csh/CES/discursos.asp. [Acesso em: 01 Out. 2018].

Pecequilo, C. S. (2011). A política externa dos Estados Unidos. Porto Alegre: Ed. UFRGS.

Pereira, P (2015). 'Os Estados Unidos e a ameaça do crime organizado transnacional nos anos 1990', Revista Brasileira de Política Internacional, 58(1), pp. 84-107.

Perry, W. Primorac, M. (1994). 'The Inter-American Security Agenda', Journal of Interamerican Studies and World Affairs, 36(3), pp. 111-127.

Pinto, P. C. A. (2015) Diplomacia e política de defesa: o Brasil no debate sobre a segurança hemisférica na década pós-Guerra Fria (1990-2000), Brasília: FUNAG.

Rodrigues, T. (2012). 'Narcotráfico e Militarização nas Américas: Vício de Guerra', Contexto Internacional, 34(1), pp. 9-41, Rio de Janeiro.

Saint-Pierre, H. L. (2011). "Defesa" ou "segurança"?: reflexões em torno de conceitos e ideologias', Contexto internacional, 33(2), pp. 407-433, Rio de Janeiro.

Smith, P. H. (2008) Talons of the Eagle: Latin América, the United States and the World. New York: Oxford University Press.

U.S. Department of State. Hemispheric Secutity. [online]. Disponível em: https://www.state.gov/p/wha/hs/index.htm [Acesso em: 13 Fev. de 2016].

United States Department of Defense (1995). Defense Ministerial of the Americas. [online]. Disponível em: http://www.summit-americas.org/Williamsburgspanish.htm. [Acesso em: 01 Out. 2018]. 


\section{Muralf}

INTERNACIONAL

Mural Internacional

V. $9 \mid$ N. 1

JAN-JUN 2018

\section{3}

United States Southern Command (2007). Posture Statement of Admiral James G. Stavridis, United States Navy Commander, United States Southern Command, before the 110th Congress House Armed Services Committee. [online]. Disponível em: https://www.globalsecurity.org/military/library/congress/2007_hr/070321stavridis.pdf [Acesso em: 01 Out. 2018].

United States Southern Command [s/d]. History. [online]. Disponível em: http://www.southcom.mil/About/History/ . [Acesso em: 30 Jan. 2017].

V Conferência de Ministros de Defesa das Américas. (2002). Declaração de Santiago de Chile [online]. Disponível em: http://www.oas.org/CSH/portuguese/docminist.asp\#VII. [ Acesso em: 01 Out. 2018].

VII Conferência de Ministros de Defesa das Américas. (2006). Declaração de Manáagua. [online]. Disponível em: http://www.oas.org/CSH/portuguese/docminist.asp\#VII. [Acesso em: 01 Out. 2018[.

Vaicius, I.; Isacson, A. (2003). The "War on Drugs" meets the "War on Terror"'. The United States' military involvement in Colombia climbs to the next level. International Policy Report.

Villa, R. D. (2014). 'O Paradoxo da Macrossecuritização: Quando a Guerra ao Terror não Securitiza Outras “Guerras” na América do Sul'. Contexto Internacional, 36(2), pp. 349-383.

Vitelli, M. (2016). 'América del Sur: de la Seguridad Cooperativa a la Cooperación Disuasoria'. Foro Internacional 225, LVI, 2016 (3), pp. 724-755. 